Hong Kong is a city of immigrants. In 1991, 77 percent of the population wemps 4 ittappe-published version born outside Hong Kong or had at least one parent born outside Hong Kong. The proportion of immigrants from mainland China or Taiwan in the local labor force was 35 percent. ${ }^{1}$ While most commentators would agree that Chinese refugees played an indispensable role in the post-War development of Hong Kong, continued influx of relatively cheap labor from China has prompted concerns about the effects of immigration on the wages of local workers. Estimating the effects of immigration in a city-economy, however, is difficult. Time-series information about the rate of immigration is not collected frequently. Moreover, the average level of wages is often dominated by secular trends as well as aggregate demand and supply conditions, so that any relationship between immigration rate and the wage level would be hard to discern. Most existing research on the effects of immigration (e.g., Grossman 1982; Borjas 1986, 1987; LaLonde and Topel 1991; Altonji and Card 1991) rely on cross-section or pooled cross-section/time-series data. In particular, variations in the fraction of immigrants across metropolitan areas are used to model the relative wages of natives and immigrants. ${ }^{2}$ Such method is obviously not applicable to Hong Kong, whose geographical area is less than 1,100 square kilometers. With the exception of the United States, few countries in the world have more than two dozen large cities that would allow this kind of inter-city analysis. This paper develops a new approach to estimating the labor market effects of immigration that does not require local labor market variations; instead it uses variations in the fraction of immigrants across age groups to model relative wages. An aggregate production function is used to study the substitution relationships between age cohorts and between immigrant groups.

In this paper the immigrant-cohort size approach is applied to empirically estimate the impact of immigration on relative wages in Hong Kong. The method is useful not only in situations in which cross-city variations are unavailable or limited. Even in countries such as the United States, the use of inter-cohort variations in immigration has advantages over the use of inter-city variations. First, the distribution of immigrants across geographical areas is not exogenous. To the extent that immigrants have a choice 
over which city to reside in, differences in relative wages across cities may not reflect the response to differences in labor supply. The mobility of immigrants across age cohorts, on the other hand, is impossible at any point in time. Moreover variations in immigration rates by age are mainly driven by human capital concerns - that is, younger immigrants can reap more benefits from their mobility decision than older immigrants can (Sjaastad 1962). Thus inter-cohort variations in relative wages are likely to reflect exogenous differences in immigration rates rather than differences in the unobserved skills of immigrants.

The second disadvantage of the cross-city approach is that it assumes local labor markets are independent of one another. General equilibrium conditions for local labor markets (e.g., Topel 1986) are ignored. This rules out the possibility that native workers may move out of the immigrant-intensive cities (Filer 1992), thereby depressing wages in the destination cities. It also rules out the possibility that capital may move across cities in response to changes in labor supplies, thereby affecting inter-city relative wages. On the other hand, the approach taken here explicitly takes into account the fact that variations in intra-cohort immigrant/native labor supplies will influence inter-cohort relative wages. This model builds on the extensive literature on the effect of cohort size on the shape of the age-earnings profile (e.g., Freeman 1979; Welch 1979). In addition to the cohort size effect, substitution between immigrants and natives within an age cohort is also modeled. The two effects are embedded in a two-stage production function so that they can be estimated together. Using a specific functional form that involves the constant-elasticity-of-substitution (CES) function, estimation and interpretation of the parameters are particularly simple.

In terms of the terminology of Borjas, Freeman, and Katz (1996), the study in this paper adopts the factor proportions approach instead of the areas approach, except that factors are classified by age cohorts rather than skill levels. Although cohort size analysis has definite advantages, there are some limitations as well. Some of these limitations will be spelled out in Section 1, where a two-stage CES labor aggregator function will be developed and discussed. The empirical work uses data from the 1991 Hong Kong 
Population Census to estimate the effect of new immigrants on other immigrants as well as on native workers. Section 2 deals with the estimation of the model, and Section 3 discusses the findings. In Section 4 the two-stage CES model is used to simulate the wage effects of raising the quota of legal immigrants from China allowed into Hong Kong.

\section{A Two-Stage CES Labor Aggregator Function}

Following the literature on the effect of cohort size on earnings (e.g., Freeman 1979; Welch 1979; Berger 1985; Berger and Allen 1988; Lee, Arthur and Rodgers 1988), workers at different age groups are viewed as imperfect substitutes to one another. In particular, I assume the aggregator function is of the CES form so that the effective total labor force is

$$
L=\left(\sum_{j=1}^{J} M_{j}^{\rho_{1}}\right)^{1 / \rho_{1}},
$$

where $M_{j}$ is the labor supply from age cohort $j$. The effective labor input from each age cohort, however, is not just a function of cohort size; the composition of workers also matters. Let $N_{j k}$ be the number of workers from immigrant group $k$ in age cohort $j$, with group $k=1$ being the native workers. I assume that the effective cohort labor force is

$$
M_{j}=\left(\sum_{k=1}^{K} N_{j k}^{\rho_{2}}\right)^{1 / \rho_{2}} .
$$

This two-stage formulation is particularly simple because only two parameters need to

be estimated. ${ }^{3}$ The parameters $\rho_{1}$ and $\rho_{2}$ are less than one (and may be negative) if the aggregator functions are concave. The aggregate production function is given by

$$
Q=F(L, K, \ldots)
$$

where $L$ is defined by (1) and (2), and $K$ is capital.

The production function specified here embodies several substantive assumptions. (1) The production function is separable in labor and the other inputs. Since there is no information concerning the use of other inputs by age or by immigrant groups, interactions between the composition of the labor force and other inputs cannot be modeled. (2) The labor aggregator function is separable in age cohorts. Thus variations 
in the native-immigrant mix within a cohort will affect wages in other cohorts only insofar as they affect the effective cohort labor supply. (3) The elasticity of substitution between any two age cohorts is constrained to be equal; similarly the elasticity of substitution between any two immigrant groups is constrained to be equal as well. This pair of restrictions greatly simplifies the estimation of the model, since only two parameters, $\rho_{1}$ and $\rho_{2}$, have to be estimated. If a more flexible functional form is used, the number of parameters to be estimated will multiply. In the sample used here, variations in $N_{j k}$ come from only 10 age cohorts and 4 immigrant groups, so it is important to limit the number of parameters to be estimated. ${ }^{4}$ Unfortunately the assumption of constant elasticity of substitution has the implication that 60-64 year-olds are as substitutable for 15-20 year-olds as 21-25 year-olds are. Contrary to what is found in LaLonde and Topel (1991), the assumption also implies that natives are equally substitutable to recent immigrants as less recent immigrants are. These limitations should be borne in mind in interpreting the CES model. (4) The sub-aggregator function for the immigrant groups in each cohort is assumed to be identical. In principle this assumption can be relaxed by allowing a different $\rho_{2}$ for every cohort $j$; in practice estimating one substitution parameter for every four immigrant group is a hazardous affair.

It is maintained in the analysis that variations in the size of immigrant-cohorts are exogenous. Hence supply shifts affect relative wages by moving along the labor demand or marginal product curves. The wage (marginal product) of immigrant group $k$ in age cohort $j$ is

$$
W_{j k}=\frac{\partial F}{\partial L} \frac{\partial L}{\partial M_{j}} \frac{\partial M_{j}}{\partial N_{j k}} .
$$

Evaluating the derivatives and taking logarithms on both sides,

$$
\log W_{j k}=\log F_{L}+\left(1-\rho_{1}\right) \log L+\left(\rho_{1}-\rho_{2}\right) \log M_{j}+\left(\rho_{2}-1\right) \log N_{j k}
$$

Except for the dependence of $\log L$ and $\log M_{j}$ on $\rho_{1}$ and $\rho_{2}$, equation (5) is a very simple linear equation and it will form the backbone of the wage model to be estimated.

The magnitudes of interest are the "elasticities of complementarity" (see, for example, Hicks 1970 and Hamermesh 1993) between various immigrant-cohort groups. They 
refer to the partial elasticities of wages with respect to changes in the supply of one factor, holding other factors unchanged. The two-stage CES formulation imposes a lot of structure to these elasticities: the elasticity of complementarity between any two groups can be derived from the two parameters $\rho_{1}$ and $\rho_{2}$ alone. Using equation (5), these elasticities are:

$$
\frac{\partial \log W_{j k}}{\partial \log N_{l m}}= \begin{cases}\left(1-\rho_{1}\right)\left(\frac{M_{l}}{L}\right)^{\rho_{1}}\left(\frac{N_{l m}}{M_{l}}\right)^{\rho_{2}}, & \text { if } l \neq j ; \\ \left(1-\rho_{1}\right)\left(\frac{M_{l}}{L}\right)^{\rho_{1}}\left(\frac{N_{l m}}{M_{l}}\right)^{\rho_{2}}+\left(\rho_{1}-\rho_{2}\right)\left(\frac{N_{l m}}{M_{l}}\right)^{\rho_{2},} & \text { if } l=j, m \neq k ; \\ \left(1-\rho_{1}\right)\left(\frac{M_{l}}{L}\right)^{\rho_{1}}\left(\frac{N_{l m}}{M_{l}}\right)^{\rho_{2}}+\left(\rho_{1}-\rho_{2}\right)\left(\frac{N_{l m}}{M_{l}}\right)^{\rho_{2}}+\left(\rho_{2}-1\right), & \text { if } l=j, m=k .\end{cases}
$$

In the above formula, the effect of $N_{l m}$ on the marginal product of aggregate labor, $F_{L}$, is ignored. In a cross section, the term $\log F_{L}$ will be absorbed in the intercept and cannot be estimated. Moreover, with 40 immigrant-cohort groups, the effect of each group on aggregate labor supply is small. Unless the production function is strongly concave in $L$, the bias will be small. ${ }^{5}$ Note also that, regardless of the bias in assuming constant marginal product of labor, the differences in the size of the coefficients associated with the cohort size terms are unbiased measures of relative wage effects.

\section{Estimating the Wage Model}

Econometric estimation of the wage model (5) can be handled by an iterative method. In a cross section of individuals, the first two terms $\log F_{L}$ and $\log L$ are identical to all workers. The third term, $\log M_{j}$, is identical to all individuals in the same age cohort. Thus, although the parameter $\rho_{2}$ enters $M_{j}$ in a non-linear fashion, the term $\log M_{j}$ can be replaced by dummy variables, $\beta_{j}$ 's, for each age cohort. With this modification, the wage equation becomes

$$
\log W_{j k}=\alpha+\beta_{j}+\left(\rho_{2}-1\right) \log N_{j k}
$$

Equation (7) is a simple linear equation and can be estimated using ordinary least squares. One minus the estimated coefficient on $\log N_{j k}$ will give a consistent (though not efficient) estimate of $\rho_{2}$.

Using the consistent estimate of $\rho_{2}$, the value of $\log M_{j}$ can be computed from equation (2). With this computed $\log M_{j}$, the wage equation (5) can be estimated 
directly, also using ordinary least squares. Fitting equation (5) gives a new estimate of $\rho_{2}$. This new estimate is used to recompute $\log M_{j}$. The process continues until the coefficients on $\log M_{j}$ and $\log N_{j k}$ converge. This method is computationally highly efficient. Only a few rounds of iterations suffice before the estimates converge.

Since individual wages depend on human capital endowments as well as factor proportions, the model has to control for demographic characteristics as well. Let the wage of individual $i$ in age cohort $j$ and immigrant group $k$ be $w_{i j k}$, and let the human capital endowment of this person be $H_{i j k}=\exp \left\{X_{i j k} \gamma\right\}$, where $X_{i j k}$ refers to the demographic

characteristics and $\gamma$ is a vector of parameters to be estimated. Assume $w_{i j k}=W_{j k} H_{i j k}$, then the wage equation to be estimated in the first step is

$$
\log w_{i j k}=\alpha+X_{i j k} \gamma+\beta_{j}+\left(\rho_{2}-1\right) \log N_{j k}
$$

and the equation to be estimated in the second step is

$$
\log w_{i j k}=\alpha+X_{i j k} \gamma+\left(\rho_{1}-\rho_{2}\right) \log M_{j}+\left(\rho_{2}-1\right) \log N_{j k}
$$

These two models are fitted to Census data in Hong Kong in the following section.

\section{Data and Estimation Results}

The data set used in this study comes from the five percent random sample file of the 1991 Hong Kong Population Census. One feature of this file is that no information about hours worked is available. The monthly income earned from main employment is used in place of the wage rate. Since women are often engaged in part-time work, the income variable need not be a good indicator of the wage rate. For the purpose of this study, I exclude female wages from the analysis. I also assume that female labor is separable from effective male labor $L$ in the aggregate production function. Thus the level of female employment can be treated just like the amount of capital and will be absorbed in the constant term of the wage equation for male workers. Including female employment will raise a potential endogeneity problem, because female labor supply is unlikely to be completely wage inelastic. 
In Hong Kong the minimum working age is fifteen. I therefore select for analysis all male employees born in Hong Kong or in China who were between 15 and 64 years of age at the time of the census. Mainland China has always been the main source of immigrants for Hong Kong. In 1991 people born in China made up about 86 percent of all non-native workers. Many foreigners who are not mainland Chinese come to work in Hong Kong only on a short term basis and have no intention of permanently staying in Hong Kong. They are not included in the analysis. Note, however, that this sample includes people born in Taiwan, as it is impossible to use census information to separate them from immigrants born in mainland Chinese. The number of such Taiwan-born persons in Hong Kong is generally believed to be small.

The sample consists of a total of 61,783 individuals. This sample of individuals is classified into 10 five-year age cohorts that range from the 15-19 age group to the 60-64 group. A person is also classified into 4 groups according to his immigration status: (1) natives (born in Hong Kong); (2) Chinese immigrants who had resided in Hong Kong for at least ten years; (3) Chinese immigrants who had resided in Hong Kong for five to nine years; and (4) Chinese immigrants who had resided in Hong Kong for less than five years. The raw count of the number of persons in these $10 \times 4$ sub-groups gives the variable $N_{j k}$ used in the wage model. Figure 1 shows the distribution of the sample by immigrant-cohort status. The fraction of natives across the age cohorts falls with age. For example, each of the youngest three cohorts consists of more than 80 percent natives, while each of the oldest four cohorts consists of less than 30 percent natives. Such a pattern reflects the rising local population base and the historical trend of the declining rate of immigration from China. In 1980 the Hong Kong government abolished the "touch-base" policy, which allowed immigrants from China to stay once they reach the urban area of Hong Kong. Legal and illegal immigration from China continued, but at a much reduced level than before.

[Figure 1 about here.]

Figure 1 also indicates that the fraction of recent immigrants (those who had lived in Hong Kong for less than ten years) is greater among the younger age groups than 
among the older age groups. For example, for those aged between 15 and 19, 10.2 percent are recent immigrants; for those aged between 60 and 64, only 1.8 percent are recent immigrants. This reflects the fact that, for human capital reasons, younger people are more likely to migrate than older people. Variations in immigrant-cohort size, then, largely arise for reasons other than variations in immigrant-cohort relative wages. As a result, the observed relationship between immigrant-cohort size and their relative wage will be on the labor demand curve rather than the supply curve. This helps to minimize the problem of endogeneity in estimating the wage model.

The wage equations (8) and (9) assume there is no cohort-specific effect that determines wages. Otherwise equation (8) will still be consistent, but equation (9) cannot be estimated because the cohort dummies and $\log M_{j}$ would be perfectly collinear. To ensure that cohort effects are unimportant, I have included an elaborate set of demographic variables $\left(X_{i j k}\right)$ in the wage equations. The variables include marital status dummies, a polynomial of degree four in work experience, a quadratic in years of schooling, and an interaction term between schooling and experience. To control for differences among the immigrant groups, I also include dummy variables for each group, as well as immigration status interacted with schooling and with experience. Such interaction terms are important because the returns to schooling for natives is substantially higher than for immigrants (Lui and Suen 1998) and the returns to measured experience is higher for natives than for immigrants (Lam and Liu 1993).

Table 1 displays the iterated least squares estimates of the two coefficients of interest in the wage regression (9). ${ }^{6}$ The parameter $\rho_{2}$ can be recovered from one plus the coefficient on $\log N_{j k}$; and $\rho_{1}$ can be recovered from $\rho_{2}$ plus the coefficient on $\log M_{j}$. These implied values are also shown in Table 1. Since the main regressors have the same values within each immigrant-cohort subgroup, the downward bias of OLS standard errors can be very large (Moulton 1986). The standard errors reported in Table 1 have been corrected for intra-group correlation.

[Table 1 about here.]

The initial estimates of $\rho_{2}$ using equation (8) are almost identical to the final esti- 
mates using equation (9). For example, with one-digit industry and occupation controls, both methods yield an estimate of .975 for the parameter $\rho_{2}$. The estimate for $\rho_{1}$, again with industry and occupation controls, is .895. The hypothesis that immigrant-cohort subgroups are perfect substitutes (i.e., $\rho_{1}=\rho_{2}=1$ ) is rejected at the .001 level with a F-statistic of 13.36 .

The negative regression coefficients suggest a negative effect of immigrant-cohort size on earnings. To see this effect more clearly, I have re-estimated the regression in column (4) of Table 1 with 40 immigrant-cohort dummies substituted for the two cohort-size terms. This regression yields a predicted log earning for each of the 40 groups that controls for human capital factors and industrial and occupational mix. I then calculate the difference in predicted log earnings between recent immigrants and natives for each age cohort as well as the difference in their log employment. Figure 2(a) plots these two variables and the weighted least squares fit for them. If the cohort size for natives in age group $j$ is $N_{j 1}$ and that for recent immigrants is $N_{j 2}$, then the weight for each age group is $1 /\left(1 / N_{j 1}+1 / N_{j 2}\right)^{1 / 2}$. The radii of the circles in Figure 2 reflect these relative weights. Figures 2(b) and 2(c) compare other immigrant groups with the natives. All three panels show a negative relationship between relative employment and relative wage. ${ }^{7}$

[Figure 2 about here.]

The estimated parameters of the two-stage CES model are not very sensitive to how workers are classified into immigrant-cohort sub-groups. For example, I have re-grouped the age categories into 5 ten-year cohorts instead of 10 five-year cohorts. Immigration status is also re-classified into 3 categories: (1) natives; (2) immigrants who had lived in Hong Kong for at least seven years; and (3) immigrants who had lived in Hong Kong for less than seven years. Seven years is used as the dividing line because immigrants who had lived in Hong Kong for more than seven years can become legal residents. Panel (B) of Table 1 shows that estimated coefficients with this coarser disaggregation of labor. With industry and occupation controls, the estimated values for $\rho_{1}$ and $\rho_{2}$ are $.935($ s.e. $=.018)$ and $.981($ s.e. $=.040)$, respectively. Since a coarser disaggregation scheme facilitates the interpretation of results, the paper will adopt $(.935, .981)$ as the 
point estimate for $\left(\rho_{1}, \rho_{2}\right)$ in what follows. The qualitative results are the same if the finer disaggregation is used.

With 15 immigrant-cohort groups, there are 225 elasticities of complementarity. All these elasticities can be calculated from the estimated $\rho_{1}$ and $\rho_{2}$. Instead of displaying a 15 by 15 matrix, Table 2 shows the estimated values of $\left(N_{l m} / M_{l}\right)^{\rho_{2}}$ and of $\left(M_{l} / L\right)^{\rho_{1}}$; so the interested reader can compute any elasticity with the formula in equation (6). The first three rows in the table may be interpreted as the fraction of effective labor supply contributed by each immigrant group to the age cohort. Similarly the last row shows the fraction of effective labor supply contributed by each age cohort to the economy. The elasticities of complementarity are functions of $\rho_{1}, \rho_{2}$, and the numbers shown in Table 2. Standard errors can be computed by the delta method, noting that the correlation between $\hat{\rho_{1}}$ and $\hat{\rho_{2}}$ is -.085 . However, the expressions in equation (6) are highly non-linear in $\rho_{1}$ and $\rho_{2}$; their partial derivatives with respect to these two parameters are rather complicated. The standard errors are therefore obtained by the parametric bootstrap method (e.g., Efron and Tibshirani 1993) instead. One thousand bivariate normal random variables are drawn using the estimated mean and covariance matrix for $\left(\hat{\rho_{1}}, \hat{\rho_{2}}\right)$. Each pair of random variables gives an estimate of the elasticity via equation (6). The sampling variability of these one thousand estimates is the bootstrap standard error.

[Table 2 about here.]

The partial elasticities of complementary are all very small, although they are statistically significant. For illustration, consider the effects of increasing the number of new immigrants in the 25-34 age cohort. A ten percent (ten log points, to be precise) increase in the supply of these workers will increase the wage of workers in other age groups by .0048 percent with a bootstrap standard error of .0013 percent. The increase in wage arises because workers in different age groups are complementary inputs. On the other hand, natives and immigrants who have been in Hong Kong for seven or more years in the 25-34 age group will experience a wage decrease of .0052 percent (s.e. $=.0097$ percent) This is because the increase in supply of new immigrants reduces the relative wage for 
that cohort. The workers most affected by the change are existing recent immigrants (who have been in Hong Kong for less than seven years) in the 25-34 age group, because they are in direct competition with the new flow of immigrants. They are expected to suffer a wage reduction of .196 percent (s.e. $=.393$ percent). These wage effects are understandably small. Table 2 indicates that recent immigrants constitute only 2.2 percent of the effective labor supply of the 25-34 year old cohort, which in turn make up 34 percent of the effective aggregate labor supply. A ten percent increase in the number of these immigrants is equivalent to a .07 percent percent increase in effective aggregate labor supply.

\section{A Policy Simulation}

Starting from 1994, the Hong Kong government increased the daily intake of Chinese immigrants from 75 to 105 . Since the additional immigrants will come from all age cohorts, the partial elasticities of complementarity (which give the wage effects of an increase in immigration in one age cohort, holding immigration in all other cohorts fixed) estimated in the previous section are only of limited use in predicting the effects of such a policy shift. The general equilibrium effects of increased immigration from all cohorts have to be analyzed. It turns out that the two-stage CES model can conveniently be used to simulate these effects.

Raising the immigration quota from 75 persons per day to 105 persons per day amounts to a 40 percent increase in the flow of immigrants. I therefore simulate the effects of a 40 percent increase in the number of recent immigrants on the labor market, noting that the short run increase in stock will be much less than 40 percent. I assume that the age distribution of the additional immigrants is the same as that of the existing recent immigrants; therefore $N_{j k}^{\prime}=1.4 N_{j k}$ for recent immigrants. With this assumption, and with the estimates for $\rho_{1}$ and $\rho_{2}$, the labor aggregate $L^{\prime}$ and the labor sub-aggregate $M_{j}^{\prime}$ can be calculated directly from the CES functions (1) and (2). From equation (5), and assuming $F_{L}$ is unchanged (see note 6 ), one obtains

$$
\Delta \log W_{j k}=\left(1-\rho_{1}\right) \Delta \log L+\left(\rho_{1}-\rho_{2}\right) \Delta \log M_{j}+\left(\rho_{2}-1\right) \Delta \log N_{j k}
$$


The standard errors are computed by the delta method.

Table 3 shows the results of the simulation. The wage effect of a 40 percent increase in immigration on natives and on immigrants who have been in Hong Kong for seven or more years is minimal: none of the estimated wage changes is larger than one-tenth of a percent. The effect on existing recent immigrants is greater, but is still not very substantial: a 40 percent increase in new immigration leads to a .66 percent reduction in the wages of recent immigrants.

[Table 3 about here.]

Since recent immigrants are a small fraction of total labor force, the elasticities with respect to effective labor supply are also computed by dividing the simulated wage effects by the change in effective labor supply $(\Delta \log L)$. These elasticities are displayed in square brackets in Table 3. Young workers (aged between 15 and 24) are hurt by increased immigration because new immigrants are predominantly young. The implied elasticity for native and earlier immigrants in the 15-24 age group is about -.02. This estimate is quite similar to the findings of research done in the United States using cross-city analysis (e.g., Borjas 1987; LaLonde and Topel 1991). However the elasticity for native and earlier immigrants in other age groups is positive. For them, the complementarity effect of increased labor supply in the youngest age group is more than enough to offset the substitution effect of increased labor supply in their same age cohort. The adverse wage effects of increased immigration are largest for existing recent immigrants, with an elasticities that range between -.63 and -.69. Note, however, that the wage effects are estimated with large standard errors. If there is no correlation within immigrant-cohort subgroups in the wage regressions, these standard errors will be reduced by about 40 percent. These simulated results should therefore be interpreted with caution.

\section{Conclusions}

This paper presents a new method of estimating the effects of immigration on the labor market. The method is particularly suitable for small economies such as Hong Kong, 
where inter-city variations in immigration are limited or unavailable. The other major advantage of this method is that exogenous variations in the size of immigrant-cohort groups are more convincing than exogenous variations in immigration across cities. With a two-stage CES model that aggregates immigrant groups into cohorts and cohorts into effective labor, the econometric estimation and the interpretation of parameters are straightforward. This paper uses data from Hong Kong to estimate the elasticities of complementarity associated with increased immigration. A simulation study is also performed that indicates increased immigration has little impact on wages. A 40 percent increase in the stock of new immigrants will lower wages by no more than one percent.

One conceptual problem that is not addressed in this paper is the issue of labor aggregation. While there is an abundance of precedents that treat immigrant groups and age groups as distinct categories of labor, a more careful handling of labor aggregation is particularly warranted here as the CES model imposes severe restrictions on substitution and complementarity relationships among the labor sub-aggregates. Alternative specifications of labor categories, such as aggregation by occupation or by education-experience groups, will test the robustness of the results presented here. 


\section{Endnotes}

1 These numbers are based on my calculations using the 1991 Population Census five percent sample file.

${ }^{2}$ Card (1990) uses the 1980 Mariel Boatlift of Cuban refugees to Miami as a "natural experiment" to study the effects of immigration. The method still relies on comparing the Miami labor market with labor markets in other cities.

3 The CES function in equation (2) can be generalized to $\left(\sum_{k} \delta_{k} N_{j k}{ }^{\rho_{2}}\right)^{1 / \rho_{2}}$. However, if there are unobserved differences in human capital endowments between the immigrant groups, the structural parameters $\delta_{k}$ 's cannot be identified in the wage equation.

4 A fully flexible functional form with constant returns would require $9 \times 8=72$ parameters to estimate the substitution between age cohorts plus $3 \times 2=6$ parameters to estimate the substitution between immigrant groups. Clearly it is not feasible to estimate 78 parameters from effectively 40 observations.

${ }^{5}$ If immigrants bring in capital as well as labor services, and assuming the amount of capital brought in per immigrant is equal to the average amount of capital owned by a native, then the reduced form $F_{L}$ will be linear when the aggregate production function is homogeneous of degree one. In that case, ignoring $F_{L}$ involves no bias.

6 The full regression estimates are available from the author. The coefficients on the demographic variables are of the expected sign and are statistically significant.

7 Note that the two-stage CES model does not constrain the wage-employment relationship to have the same slope across different immigrant groups. 


\section{References}

Altonji JG, Card D (1991) The Effects of Immigration on the Labor Market Outcomes of Less-skilled Natives. In: Abowd JB, Freeman RB (eds) Immigration, Trade, and the Labor Market. University of Chicago Press, Chicago, 210-234

Berger MC (1985) The Effect of Cohort Size on Earnings Growth: A Reexamination of the Evidence. Journal of Political Economy 93(3): 561-573

—, Allen JF (1988) Black-White Earnings Ratios: The Role of Cohort Size Effects. Economics Letters 26: 285-290

Borjas GJ (1986) The Sensitivity of Labor Demand Functions to Choice of Dependent Variable. Review of Economics and Statistics 68(1): 58-66

— (1987) Immigrants, Minorities, and Labor Market Competition. Industrial and Labor Relations Review 40: 382-393

—, Freeman RB, Katz LF (1996) Searching for the Effect of Immigration on the Labor Market. American Economic Review 86(2): 246-251.

Card D (1990) The Impact of the Mariel Boatlift on the Miami Labor Market. Industrial and Labor Relations Review 43(1): 245-257

Efron B, Tibshirani RJ (1993) An Introduction to the Bootstrap. Chapman \& Hall, New York

Filer RK (1992) The Effect of Immigrant Arrivals on Migratory Patterns of Native Workers. In: Borjas GJ, Freeman RB (eds) Immigration and the Work Force. University of Chicago Press, Chicago, 245-269

Freeman RB (1979) The Effect of Demographic Factors on Age-Earnings Profiles. Journal of Human Resources 14: 289-318

Grossman J (1982) The Substitutability of Natives and Immigrants in Production. Review of Economics and Statistics 64: 596-603 
Hamermesh DS (1993) Labor Demand. Princeton University Press, Princeton

Hicks J (1970) Elasticity of Substitution Again: Substitutes and Complements. Oxford Economic Papers 22: 289-296

LaLonde RJ, Topel RH (1991) Labor Market Adjustments to Increased Immigration. In: Abowd JB, Freeman RB (eds) Immigration, Trade, and the Labor Market. University of Chicago Press, Chicago, 167-199

Lam KC, Liu PW (1993) Are Immigrants Assimilating Better Now than a Decade Ago? Hong Kong Institute of Asia-Pacific Studies Occasional Paper No. 31

Lee RD, Arthur WB, Rodgers G (eds) Economics of Changing Age Distributions in Developed Countries. Oxford University Press, Oxford

Lui HK, Suen W (1998) Does Schooling in China Yield Lower Returns than Schooling in Hong Kong? Asian Economic Journal (forthcoming)

Moulton BR (1986) Random Group Effects and the Precision of Regression Estimates. Journal of Econometrics 32: 385-397

Sjaastad L (1962) The Costs and Returns to Human Migration. Journal of Political Economy 70: 80-93

Topel RH (1986) Local Labor Markets. Journal of Political Economy 94: S111-S143

Welch F (1979) Effects of Cohort Size on Earnings: The Baby Boom Babies' Financial Bust. Journal of Political Economy 87: S65-S97 


\title{
Estimating the Effects of Immigration in One City
}

\author{
Wing Suen* \\ School of Economics and Finance, The University of Hong Kong \\ Pokfulam Road, Hong Kong \\ Fax: +852 2548-1152 \\ E-mail: hrneswc@hkusua.hku.hk
}

August 18, 1998

Abstract. This paper presents a new method of estimating the effects of immigration on the labor market that does not require variations in immigration across cities. With a two-stage CES model that aggregates immigrant groups by age cohorts and aggregates cohorts into effective labor, the econometric estimation and the interpretation of parameters are particularly straightforward. The paper uses data from Hong Kong to estimate the elasticities of complementarity associated with increased immigration. A simulation study indicates that a 40 percent increase in the stock of new immigrants will lower wages by no more than one percent.

JEL classification: J23, J31, J61

Key words: immigrant-cohort size, two-stage CES model, elasticity of complementarity

* I would like to thank Doug Allen, William Chan, Don DeVoretz, and a referee for their useful comments. 
Table 1

Iterated Least Squares Estimates of CES Wage Model

A. 10 Age Cohorts $\times 4$ Immigrant Status

\begin{tabular}{lcccc} 
Variables & $(1)$ & $(2)$ & $(3)$ & $(4)$ \\
\hline $\log N_{j k}$ & -.0314 & -.0319 & -.0261 & -.0255 \\
& $(.0312)$ & $(.0299)$ & $(.0221)$ & $(.0212)$ \\
$\log M_{j}$ & -.0978 & -.0907 & -.0828 & -.0793 \\
& $(.0434)$ & $(.0422)$ & $(.0278)$ & $(.0271)$ \\
implied $\rho_{1}$ & .8708 & .8773 & .8911 & .8952 \\
& $(.0283)$ & $(.0279)$ & $(.0206)$ & $(.0203)$ \\
implied $\rho_{2}$ & .9686 & .9681 & .9739 & .9745 \\
& $(.0312)$ & $(.0299)$ & $(.0221)$ & $(.0212)$ \\
industry dummies & no & yes & no & yes \\
occupation dummies & no & no & yes & yes \\
s.e.e. & .464 & .461 & .432 & .429 \\
$R^{2}$ & .409 & .417 & .488 & .495 \\
\hline
\end{tabular}

B. 5 Age Cohorts $\times 3$ Immigrant Status

\begin{tabular}{lcccc} 
Variables & $(1)$ & $(2)$ & $(3)$ & $(4)$ \\
\hline $\log N_{j k}$ & -.0264 & -.0261 & -.0188 & -.0190 \\
& $(.0545)$ & $(.0507)$ & $(.0425)$ & $(.0401)$ \\
$\log M_{j}$ & -.0384 & -.0360 & -.0487 & -.0462 \\
& $(.0658)$ & $(.0613)$ & $(.0507)$ & $(.0480)$ \\
implied $\rho_{1}$ & .9351 & .9379 & .9326 & .9348 \\
& $(.0266)$ & $(.0247)$ & $.0191)$ & $(.0176)$ \\
implied $\rho_{2}$ & .9736 & .9739 & .9812 & .9810 \\
& $(.0545)$ & $(.0507)$ & $(.0425)$ & $(.0401)$ \\
industry dummies & no & yes & no & yes \\
occupation dummies & no & no & yes & yes \\
s.e.e. & .466 & .462 & .433 & .430 \\
$R^{2}$ & .405 & .414 & .486 & .493 \\
\hline
\end{tabular}

Standard errors are corrected for correlation within immigrantcohort subgroups and are shown in parentheses. 


\section{Table 2}

Fraction of Effective Labor Supply From Immigrant-Cohort Groups

\begin{tabular}{lccccc}
\hline$\left(N_{l m} / M_{l}\right)^{\rho_{2}}$ & $15-24$ & $25-34$ & $35-44$ & $45-54$ & $55-64$ \\
\hline natives & .833 & .778 & .568 & .252 & .184 \\
immigrants $(\geq 7$ years $)$ & .121 & .200 & .413 & .728 & .802 \\
immigrants $(<7$ years) & .046 & .022 & .020 & .020 & .014 \\
\hline$\left(M_{l} / L\right)^{\rho_{1}}$ & .169 & .340 & .252 & .136 & .102 \\
\hline
\end{tabular}




\section{Table 3}

Effect of a 40 Percent Increase in Recent Immigrants on Wages

\begin{tabular}{lccccc}
\hline & $15-24$ & $25-34$ & $35-44$ & $45-54$ & $55-64$ \\
\hline natives & $-.021 \%$ & $.023 \%$ & $.027 \%$ & $.027 \%$ & $.037 \%$ \\
& $(.053 \%)$ & $(.016 \%)$ & $(.015 \%)$ & $(.015 \%)$ & $(.017 \%)$ \\
& {$[-.022]$} & {$[.024]$} & {$[.028]$} & {$[.028]$} & {$[.038]$} \\
immigrants ( $\geq 7$ years) & $-.021 \%$ & $.023 \%$ & $.027 \%$ & $.027 \%$ & $.037 \%$ \\
& $(.053 \%)$ & $(.016 \%)$ & $(.015 \%)$ & $(.015 \%)$ & $(.017 \%)$ \\
& {$[-.022]$} & {$[.024]$} & {$[.028]$} & {$[.028]$} & {$[.038]$} \\
immigrants (<7 years) & $-.662 \%$ & $-.618 \%$ & $-.614 \%$ & $-.614 \%$ & $-.604 \%$ \\
& $(.553 \%)$ & $(.578 \%)$ & $(.581 \%)$ & $(.580 \%)$ & $(.586 \%)$ \\
& {$[-.687]$} & {$[-.641]$} & {$[-.637]$} & {$[-.638]$} & {$[-.627]$} \\
\hline
\end{tabular}

Asymptotic standard errors are in parentheses. Figures in brackets are elasticities with respect to the change in effective total labor supply. 
Fig. 1.

Distribution of Sample by Immigration and Cohort Status

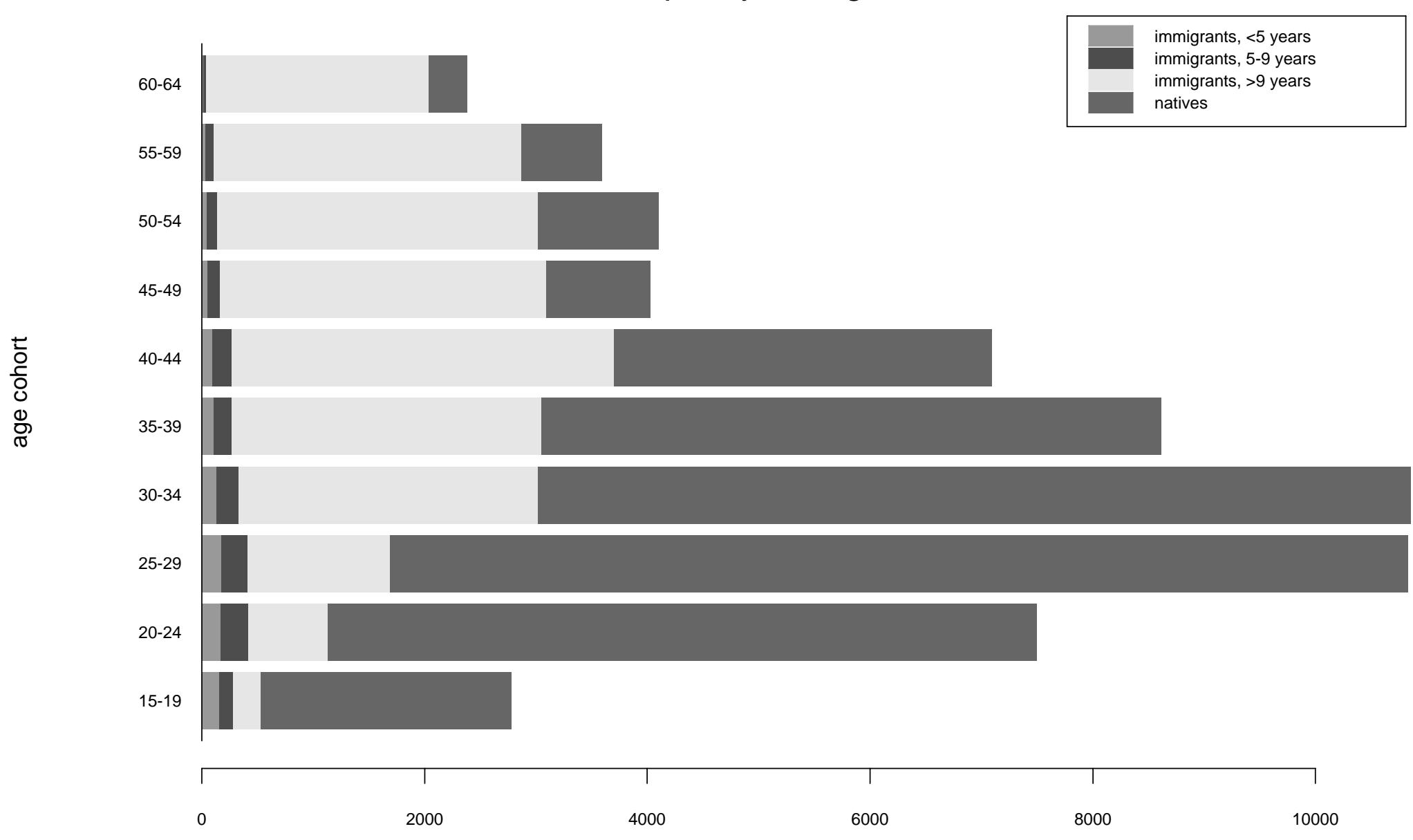


Fig. 2.

Relative Employment and Relative Earnings for Immigrants and Natives

(a) Immigrants ( $<5$ Years) v. Natives

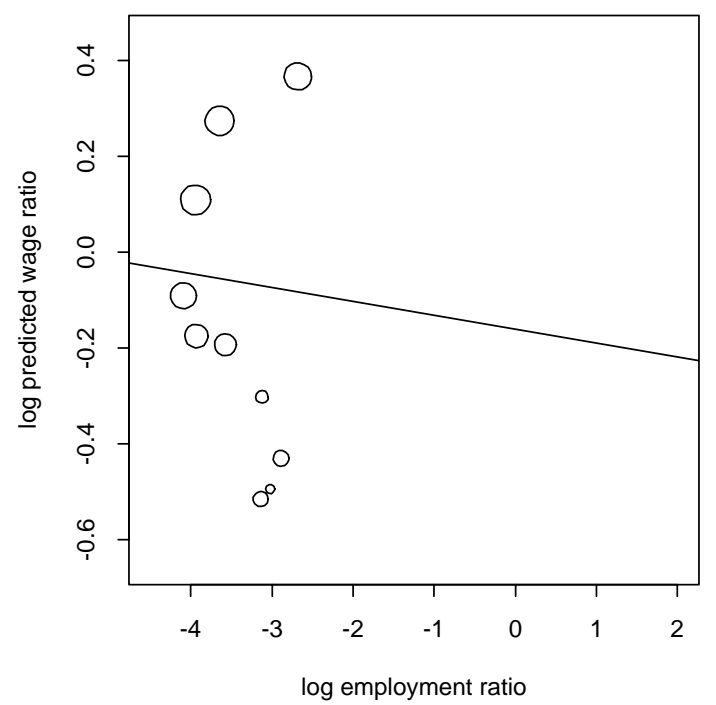

(b) Immigrants (5-9 Years) v. Natives

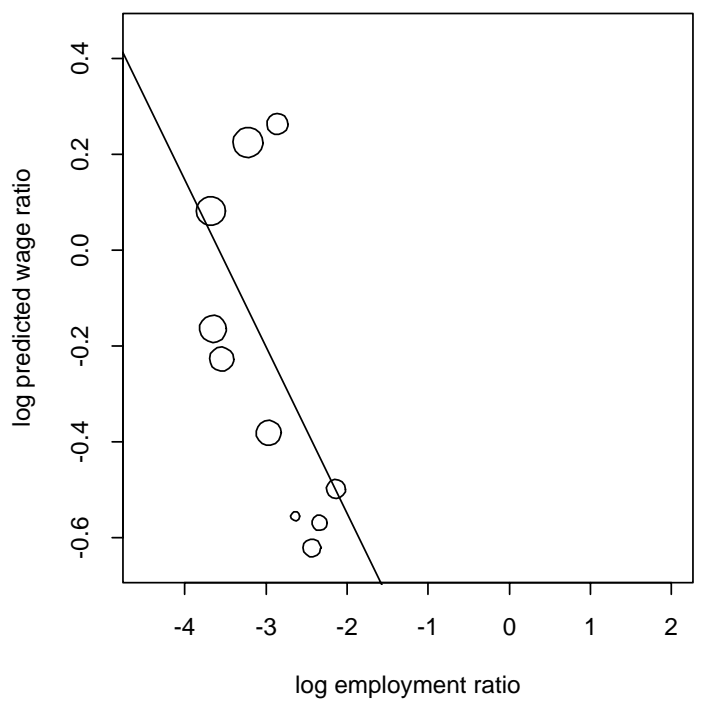

(c) Immigrants (>9 Years) v. Natives

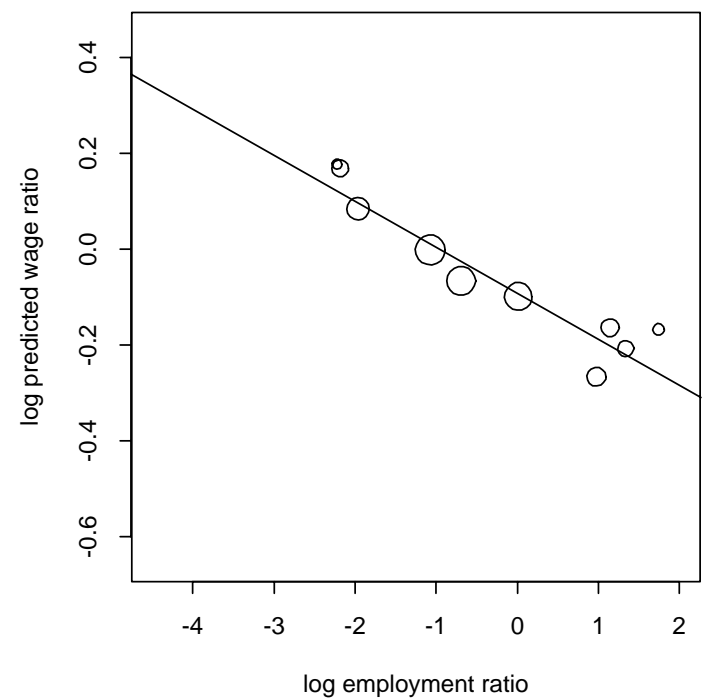

